\title{
BENCH-SCALE EXTRACTION OF STILBENOIDS AND OTHER PHENOLICS FROM STORED GRAPE CANES (VITIS VINIFERA): OPTIMIZATION PROCESS, CHEMICAL CHARACTERIZATION, AND POTENTIAL PROTECTION AGAINST OXIDATIVE DAMAGE
}

\author{
SEBASTIAN RIQUELME ${ }^{1,2}$, VANIA SAEZZ ${ }^{2}$ DANILO ESCOBAR ${ }^{1}$, CAROLA VERGARA ${ }^{2}$, CECILIA FUENTEALBA ${ }^{1}$, \\ LUIS BUSTAMANTE ${ }^{2}$, DIETRICH VON BAER ${ }^{2}$, PAOLA JARA ${ }^{3}$, LILIANA LAMPERTI $^{3}$, CLAUDIA MARDONES ${ }^{2, *}$ \\ ${ }^{1}$ Unidad de Desarrollo Tecnológico, Universidad de Concepción, Coronel, Chile \\ ${ }^{2}$ Departamento de Análisis Instrumental, Facultad de Farmacia, Universidad de Concepción, Concepción. Chile \\ ${ }^{3}$ Departamento de Bioquímica e Inmunología, Facultad de Farmacia, Universidad de Concepción, Concepción, Chile
}

\begin{abstract}
Dietary supplements have become the key to complement deficiencies in the occidental diet and therefore to reduce the incidence of oxidative stress related diseases. A bench-scale extraction procedure was studied to obtain a valuable product rich in phenolic compounds and antioxidant capacity from Pinot Noir grape cane enhanced by storage. Extraction solvent, cane-size, solid:liquid ratio, temperature, and extraction time, were systematically evaluated in order to obtain a natural functional product. Complete chemical characterization of a Pinot Noir grape cane extract produced under bench scale process is presented for the first time. Phenolic profiles of the extracts were characterized by HPLC-PDA-MS/MS and minerals by ICP-OES. Proteins, carbohydrates and lignins were also evaluated. The main phenolic compounds in the final product were stilbenoids, flavan-3-ols, procyanidins, and flavonols, with $6.53 \%, 4.84 \%, 2.11 \%$, and $0.25 \%$, respectively on a dry matter basis. Other chemical constituents were carbohydrates $(27 \%)$, minerals $(1 \%)$ and lignins $(38.7 \%)$. The antioxidant capacity of the product was demonstrated using chemical assays (TEAC $\mathrm{ABTS}_{\mathrm{CUPRAC}}$ and ORAC-FL) and endothelial cells model. The extract produced under the described bench scale process using grape cane enhanced by storage have a chemical composition and protecting capacities to be used in functional foods industry.
\end{abstract}

Keywords: Stilbenoids, Procyanidins, Grape canes, Bench-scale extraction, Antioxidant capacity.

\section{INTRODUCTION}

Research on phytoalexins as nutritional components to promote health benefits have triggered the interest to obtain them at industrial scale with an ecofriendly process ${ }^{1}$.

Health-promoting properties of many stilbenoids have been reported, including antioxidant, anti-inflammatory, anticarcinogenic, and neuroprotective effects $^{2}$. Procyanidins are also known for their antioxidants, anti-inflammatory and antimicrobial properties, beside cardioprotective, hepatoprotective and neuroprotective effects ${ }^{3-6}$.

Viticulture by-products have been extensively studied because of their interesting stilbenoids profiles and levels ${ }^{7}$. The levels of stilbenoids and the storage conditions of cane after the pruning in several $V$. vinifera varieties cultivated in Chile have also been reported ${ }^{8,9}$.

Stilbenoid extraction from grape canes and other lignocellulosic matrices has also been investigated. Karacabey et al. ${ }^{10}$ optimized the solid-liquid extraction conditions for obtaining stilbenoids from grape canes, using $54 \%$ of ethanol in water at $83.6{ }^{\circ} \mathrm{C}$. They also modeled the supercritical solid-liquid extraction kinetics of $E$-resveratrol and $E$ - $\varepsilon$-viniferin from Pinot Noir grape canes $^{11}$. An evaluation of laboratory scale ultrasound-extraction of stilbenoids from grape stems concluded that the most significant variables of the process were solvent composition and sample-solvent ratio, where the optimal extraction conditions were solvent composition of $80 \%$ ethanol and $75^{\circ} \mathrm{C}$ during $15 \mathrm{~min}$ of sonication $^{12}$.

The main aim of this study is to develop a bench scale extraction process for the scale-up production of a functional crude ingredient containing stilbenoids and procyanidins, from stored grape canes. The scaling up of a solid-liquid analytical extraction method to a bench scale process was optimized for this purpose. The complete chemical characterization and determination of the antioxidant properties of the final dry extract, with emphasis on the phenolic constituents, was carried out in order to promote the use of this viticulture residue toward the functional food industry.

\section{Materials and methods}

\subsection{Sample material}

The study was performed using $V$. vinifera canes cv Pinot Noir obtained during commercial pruning of healthy plants from an organic vineyard, "Viña de Neira" located in Biobio region, south Chile (36³6'50.33" S, 72³9'40.63" W at an altitude of $279 \mathrm{~m}$ ). The vines were pruned in August 2012 and the canes were collected from the soil after one week, which were immediately transported for storage and analysis. Gorena et al. ${ }^{9}$ previously described that the stilbenoids level in grape canes is subjected to changes in time. Due to that, in order to compensate this increase in the concentration during the optimization of the extraction process, the stilbenoids levels were normalized using the results obtained by the analytical extraction carried out in parallel with the same material. The samples were stored over 3 months at $19^{\circ} \mathrm{C} \pm 5$ and $70 \%$ humidity-(patent 201403417 ), to obtain the lyophilized bench-scale extract which significantly increased the levels of stilbenoids in the raw material before the definitive extraction. The raw stored material was milled using hammer mill (Condux-Werk LS 10M, Wolfgang/Hanau, Germany).

\subsection{Reagents and solvents}

HPLC-grade acetonitrile, and water, ethanol, piceatannol (95\%), cupric chloride dihydrate, ammonium acetate, calcium carbonate, sulfuric and formic acids were obtained from Merck (Darmstadt, Germany). Potable ethanol (98\%) was obtained from Oxiquim (Concepción, Chile) for bench-scale extractions. $E$ resveratrol (99\%), E- $\varepsilon$-viniferin $(98 \%)$ and Procyanidin B2 $(100 \%)$ were obtained from Phytolab (Vestenbergsgreuth, Germany). Hopeaphenol, E-vitisin$\mathrm{B}$, and vitisin-A were obtained from TU Braunschweig, Germany. An Oxiselect ${ }^{\mathrm{TM}} \mathrm{Kit}$ for ORAC-FL method was obtained from Cell Biolabs, Inc. (San Diego, USA). (+)-Catechin hydrate ( $>98 \%)$, (-)-epicatechin $(>90 \%)$, quercetin-3L-rhamnoside $(85 \%)$, quercetin-3-rutinoside $(<94 \%)$, quercetin, kaempferol (90\%), 6-hydroxy-2,5,7,8-tetramethylchroman-2-carboxylic acid (Trolox), neocuproine hemihydrate, 3-ethylbenzothiazoline-6-sulfonic acid (ABTS), potassium persulfate, monosaccharide standards, namely l-(+)-arabinose $(99 \%)$, 1-(-)-rhamnose monohydrate $(99 \%), d-(+)$-glucose $(99.5 \%), d-(+)$-galactose $(99 \%), 1-(-)$-mannose $(99 \%), d-(-)$-xylose $(99 \%), d$-(-)-fructose $(99 \%)$ were purchased from the Sigma-Aldrich Chemical Co. (St. Louis, USA).

\subsection{Extractions}

Extraction procedures were performed at analytical and bench scale level, taking the first as a reference for the maximum amount of stilbenoids that can be extracted from each grape cane sample using ethanol/water $80: 20 \mathrm{v} / \mathrm{v}^{8-11}$.

\subsection{Analytical-scale extractions}

The analytical extractions were performed using ultrasonic bar homogenizer (Cole Palmer Series 4710, Chicago, USA), $80 \% \mathrm{v} / \mathrm{v}$ of ethanol/water mixture and milled grape cane material, the procedure described by our research group ${ }^{8,9}$. All portions were collected and before chromatographic analysis, the samples were diluted in mobile phase and filtered through a PES filter $0.22 \mu \mathrm{m}$.

The stilbenoids concentration of the stored grape canes were monitored between 2 and 9 months after commercial pruning, in order to reach the highest level of stilbenoids for the definitive bench scale extraction ${ }^{9}$. 


\subsection{Bench-scale extractions}

Ultrasonic assistance was avoided in all bench-scale extractions. The study was carried out in stainless-steel hermetic reactors of 1 and $7 \mathrm{~L}$, equipped with temperature and pressure sensor, in order to develop a better optimization of the scaling-up process ${ }^{13}$. A preliminary study of solid: liquid $(\mathrm{S}: \mathrm{L})$ ratio and temperature was carried out in the $1 \mathrm{~L}$ reactor. S:L ratio of $1: 15,1: 10$ and $1: 3$ at $20^{\circ} \mathrm{C}, 80^{\circ} \mathrm{C}$ and $150^{\circ} \mathrm{C}$ were studied.

-Grape cane size, time and extraction temperature on the stilbenoids yield were studied as follows:

-Grape canes chopped to $0.5,1.0$, and $2.0 \mathrm{~cm}$ were extracted at $80^{\circ} \mathrm{C}$ for 65 $\mathrm{min}$ in the $1 \mathrm{~L}$ stainless-steel reactor using a $\mathrm{S}: \mathrm{L}$ ratio of $1: 10$.

-Temperature and extraction time were evaluated in a $7 \mathrm{~L}$ reactor. A first extraction was carried out using ethanol $80 \%$ and $S: L$ ratio $1: 10$ and $1 \mathrm{~cm}$ long canes pieces.

Considering the time required to heat $7 \mathrm{~L}$ of solvent, the extraction process was divided in two stages, the first one, a heating period where the temperature of the solvent in contact with the biomass was raised to $108^{\circ} \mathrm{C}$; and the second one where the extraction temperature was kept constant at around $108^{\circ} \mathrm{C}$, reaching a total time of $150 \mathrm{~min}$. During the heating and extraction steps the concentration of each stilbenoid was determined and normalized as the extraction yield obtained, considering the analytical extraction.

A second extraction was carried out under the same conditions except for temperature which was set at $80^{\circ} \mathrm{C}$. The whole process was monitored carefully. In order to evaluate the effect of consecutive extractions over the accumulated concentration, three consecutive extraction steps using "fresh" solvent were applied and evaluated. The extraction was performed under the best condition obtained ( $80 \%$ ethanol, chopped canes of $1 \mathrm{~cm}, \mathrm{~S}: \mathrm{L}$ ratio $1: 10$ and $80^{\circ} \mathrm{C}$ for 100 min). Finally, under these conditions the definitive bench scale extraction was carried out using the grape cane enhanced by storage.

\subsection{Lyophilized bench-scale extract (LBSE)}

After the extraction procedure was established, 5L of the obtained crude extract was filtered and ethanol was removed using a rotavapor at $37{ }^{\circ} \mathrm{C}$. The aqueous extract was lyophilized (Freeze dryer system, Alpha 2-4 LD plus, Christ, Osterode, Germany) to give $71.135 \pm 0.001 \mathrm{~g}$ of solid extract for characterization. This product is referred to as lyophilized bench-scale extract (LBSE).

\subsection{Analytical methods}

\subsubsection{Determination of stilbenoids and other phenolic compounds}

The extracts were analyzed using a Shimadzu Nexera UHPLC/HPLC system (Kyoto, Japan), coupled in tandem with mass spectrometry detector (QTrap 3200, AB Sciex, Dublin,USA) for identification and Shimadzu Nexera diode array detector (DAD) (Kyoto, Japan) for quantification. Instrument control and data collection were performed using a Class-VP DAD software and Analyst software (Version 1.5.2, Shimadzu Co., Kyoto, Japan). The separation and electrospray ionization conditions for qualitative analysis were those described by Gorena et al. ${ }^{9}$. Quantifications were performed using DAD detector by external calibration curves at $280 \mathrm{~nm}$ for flavan-3-ols and procyanidins, $306 \mathrm{~nm}$ for stilbenoids, and $360 \mathrm{~nm}$ for flavonols, using the standards of $E$-resveratrol, $E$ - $\varepsilon$-viniferin and $E$-piceatannol for stilbenoids, $(+)$-catechin for flavan-3-ols and procyanidins, and quercetin for flavonols. The analytical parameters of the method are summarized in Table 1.

Table 1. Analytical parameters for phenolic compound quantification using HPLC-DAD.

\begin{tabular}{|c|c|c|c|c|c|c|}
\hline Compound & Standard & $\begin{array}{c}\text { Response } \\
(\mathrm{mAU})\end{array}$ & $R^{2}$ & $\begin{array}{c}\text { Linear range } \\
\left.(\mu \mathrm{mol} \mathrm{g})^{-1}\right)\end{array}$ & $\begin{array}{c}\text { LOD } \\
\left.(\mu \mathrm{mol} \mathrm{g})^{-1}\right)\end{array}$ & $\begin{array}{c}\text { LOQ } \\
\left.(\mu \mathrm{mol} \mathrm{g})^{-1}\right) \\
\end{array}$ \\
\hline \multirow[t]{3}{*}{ Stilbenoids } & (E)-Resveratrol & $y=44079207 x-34452$ & 0.9999 & $0.009-0.491$ & 0.003 & 0.009 \\
\hline & (E)-Viniferin & $y=76894 x-48492$ & 0.9983 & $0.005-0.136$ & 0.002 & 0.005 \\
\hline & (E)-Piceatannol & $y=138884 x-129139$ & 0.9984 & $0.013-0.205$ & 0.004 & 0.013 \\
\hline Flavonols & Quercetin 3-glucoside & $y=455776 x-419.91$ & 0.9996 & $0.020-0.323$ & 0.006 & 0.020 \\
\hline \multirow[t]{2}{*}{ Procyanidins } & Catechin & $y=17815 x-1792$ & 0.9996 & $0.008-0.134$ & 0.003 & 0.008 \\
\hline & Epicatechin & $y=17619 x-2414$ & 0.9997 & $0.007-0.134$ & 0.002 & 0.007 \\
\hline
\end{tabular}

$R^{2}$ : correlation coefficient; LOD: limit of detection; LOQ: limit of quantification.

\subsubsection{Determination of carbohydrates and lignins in LBSE.}

The LBSE was processed using the procedure described by Sluiter et al. ${ }^{14}$.The hydrolyzed carbohydrates were analyzed using an HPLC with refractive index detector (RID) Prominence (Shimadzu Co., Kyoto, Japan). The chromatographic column was an Aminex HPX-87H (Biorad, Hercules, CA, USA). The compounds were identified by comparison of their retention times with standards, and quantified by external calibration.

Insoluble lignins were analyzed using the procedure described by Sluiter et al. ${ }^{14}$. The absorptivity used for the calculation was $110 \mathrm{~cm}^{2} \mathrm{mg}^{-1}$.

The average molecular weight (MW) of the insoluble lignins was determined by gel permeation chromatography (GPC) under the condition described by $\mathrm{Ku}$ et al. ${ }^{15}$, using a Prominence HPLC with UV-Vis detector (Shimadzu, Japan). Two $5 \mu \mathrm{m}$ Phenogel columns coupled in series were used. The pore size of the first and the second columns were $1 \times 10^{6} \AA$ and $1 \times 10^{3} \AA$ respectively. All columns were provided by Phenomenex (Torrance, CA, USA). The calibration curve was constructed using polystyrene standards (GPC/SEC Calibration Kit, Agilent Technologies, Santa Clara, USA).

\subsubsection{Determination of metals in LBSE}

The samples were analyzed using inductively coupled plasma-optical emission spectroscopy (Optima 7000 DV, PerkinElmer, Waltham, MA, USA), as described in UNE-CEN 15290 for determination of $\mathrm{Ca}, \mathrm{Fe}, \mathrm{Mg}$, and $\mathrm{K}$, and in UNE-CEN 15297 for $\mathrm{As}, \mathrm{Cu}, \mathrm{Pb}$, and $\mathrm{Zn}$. The LBSE was hydrolyzed using a microwave digester (Mars 240/50, CEM Corporation, Matthews, NC, USA) ${ }^{16}$.

\subsubsection{LBSE in vitro antioxidant capacity assays}

The antioxidant assays were performed using a micro-volume spectrophotometer (Epoch Biotek System, Winooski, VT, USA). Standards solutions of these main compounds were prepared individually and mixed, at the same concentration level found in the extract, with the aim to compare their antioxidant capacities.

TEAC $_{\text {CUPRAC }}$ assays were performed as described by Ribeiro et al. $2011^{17}$. $\mathrm{TEAC}_{\mathrm{ABTS}}$ and the ORAC-FL assay was conducted according to the methodology described by Karacabey et al. $2010^{18}$. Reactive oxygen species (ROS) detection was performed using a dichloro dihydro fluorescein diacetate (DCF-DA) probe: ECV-304 endothelial cells were cultivated using 199 medium supplemented with $10 \%$ fetal bovine serum (Sigma-Aldrich) in a $5 \% \mathrm{CO}_{2}$ atmosphere. The cells were pre-incubated with a DCF-DA $(5 \mu \mathrm{M})$ solution probe for $30 \mathrm{~min}$. Several samples dilutions were added and incubated for additional $24 \mathrm{~h}$. The fluorescence emission was measured using an excitation wavelength of $485 \mathrm{~nm}$ and emission wavelength of $540 \mathrm{~nm}$. The results were expressed as DCF fluorescence intensity per cell protein content ${ }^{19}$. The samples and standards were diluted in order to fit the linear range and were analyzed by triplicate. 


\section{RESULTS AND DISCUSSION}

\subsection{Operating condition for bench-scale extractions}

Stilbenoid extraction yields were determined for each experiment to identify the best conditions for bench-scale cane extraction. In the preliminary $1 \mathrm{~L}$ study, the $\mathrm{S}: \mathrm{L}$ ratio and temperature were evaluated. S:L ratio of $1: 15$ yielded $76 \pm 2 \%$ of stilbenoids, while for $1: 10$ and $1: 3$, the yields were $68 \pm 1 \%$ and $39 \pm 1 \%$, respectively. The optimum condition was considered to have the highest extraction yield with a lowest possible amount of solvents that later must be evaporated and thus, a proportion of 1:10 was selected. The influence of temperature indicated that at $20^{\circ} \mathrm{C}$ and $150^{\circ} \mathrm{C}$ there was a considerable decrease in the extraction yield, while at $80^{\circ} \mathrm{C}$ the highest stilbenoid yield was reached $(68 \%)$. These results are in accordance with other authors as Karacabey \& Mazza $^{10}$.

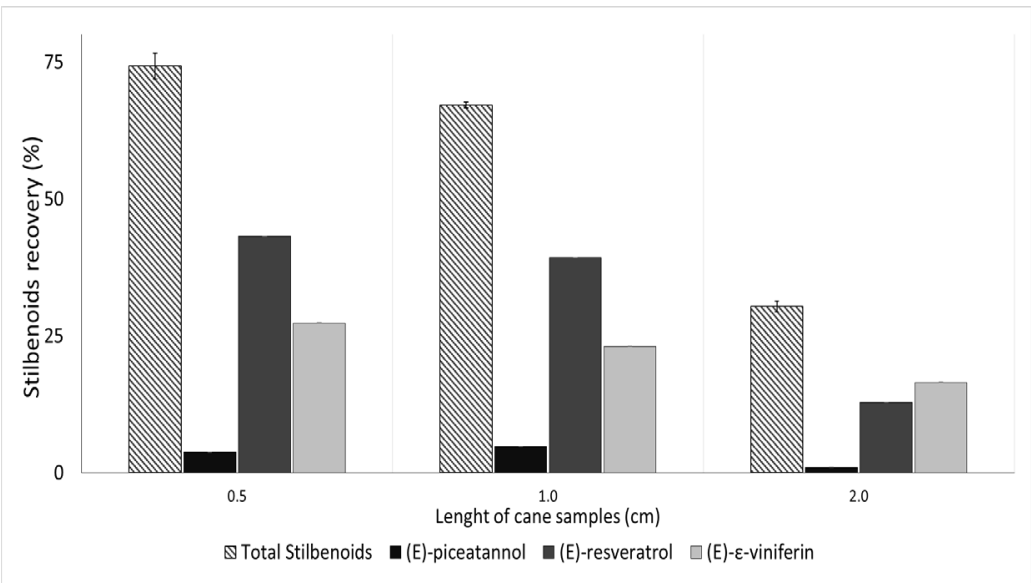

Figure 1. Recovery of stilbenoids in bench-scale extraction effect of cane sample length.

Figure 1 shows the extraction recovery obtained when cane samples of different lengths were subjected to the extraction procedure, the results were normalized through analytical extraction yield and expressed in average \pm standard deviation. The extraction yield increased with decreasing sample size, in agreement with the results reported for phenolic compounds ${ }^{20,21}$. The reduction of sample size from 2.0 to $1.0 \mathrm{~cm}$, increased the extraction yield in $37 \pm 1 \%$, while the reduction from 1.0 to $0.5 \mathrm{~cm}$ increased only $7 \pm 1 \%$ the extraction. Therefore, subsequent experiments were performed with cane pieces of $1.0 \mathrm{~cm}$; this represents a good compromise between cost (energy required for the mill step ${ }^{22}$ ) and efficiency in the scope of industrial scale-up.

The influence of the heating process from the beginning of the extraction, and the effect of temperature on stilbenoid stability in the extract were evaluated in a $7 \mathrm{~L}$ extraction in two steps. Four samples were collected during the heating step, and another four during the final extraction, spaced roughly every $25 \mathrm{~min}$. The results are presented in Figure 2A. The highest concentrations were obtained at around $165 \mathrm{~min}$ from the beginning of the extraction process; this is $50 \mathrm{~min}$ after the extraction temperature $\left(108^{\circ} \mathrm{C}\right)$ was reached. At this point the extraction yield was approximately $72 \%$ of the stilbenoids from the grape cane matrix. As expected, high temperature results in better solvent penetration into the grape cane matrix, by reducing the solvent viscosity and surface tension, which increases the stilbenoid diffusion from the matrix. All these processes may have helped to increase the stilbenoid concentration in the extract up to $165 \mathrm{~min}$, after which it decreased to $53 \%$ yield, probably due to thermal degradation of the compounds.

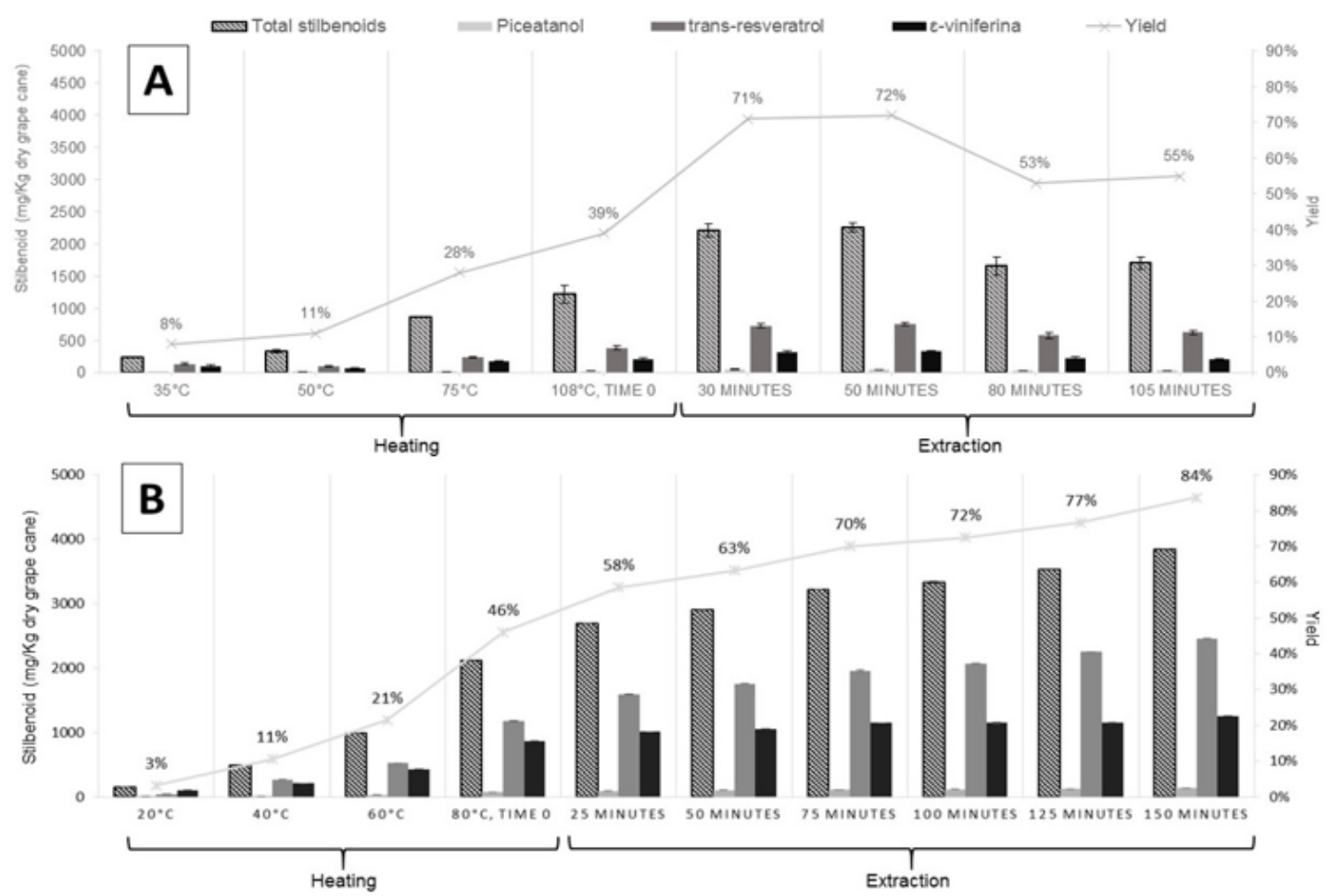

Figure 2. Extraction of stilbenoids from grape canes (A) with heating to $108^{\circ} \mathrm{C}$ and (B) heating at $80{ }^{\circ} \mathrm{C}$. 
Another unwanted effect produced at this temperature and time was a high pressure in the reactor caused by ethanol evaporation (pressure was monitored but not controlled). Considering as final objective the industrial scale up of the process, the use of these conditions requires a more complex infrastructure and higher energy input, which would increase the costs. Therefore, a second experiment was performed under the same conditions, except that the temperature was lowered to $80^{\circ} \mathrm{C}$, to avoid an increase in pressure, and to compensate the extraction time was extended to $150 \mathrm{~min}$. As Figure $2 \mathrm{~B}$ shows, the stilbenoid concentration did not decrease at this temperature, despite the increase in the extraction time; moreover, the stilbenoid levels increased to $84 \%$ in $150 \mathrm{~min}$ at $80^{\circ} \mathrm{C}$.

Considering these results, and to avoid thermal degradation of stilbenoids and maximize the extraction yield, the use of consecutive extraction steps for the same sample portion was evaluated in order to maximize the depletion of stilbenoids from grape canes. With a second extraction, it was possible to increase the amount of stilbenoids extracted in the first step by $39 \%$, while a third extraction, only $4 \%$ of increase was produced. It was observed that the proportion of each stilbenoid in each extraction step did not change; the extracted stilbenoids of both accumulative extractions were $2868 \mathrm{mg} \mathrm{Kg}^{-1}$ dry grape cane, $3466 \mathrm{mg}$ $\mathrm{Kg}^{-1}$ dry grape cane and $114 \mathrm{mg} \mathrm{Kg}^{-1}$ dry grape cane for $E$-resveratrol, $E$ - $\varepsilon$ viniferin, and $E$-piceatannol, respectively, representing an extraction percentage of $100 \pm 4 \%, 87 \pm 4 \%$, and $47 \pm 3 \%$ respect to the concentration obtained applying analytical extraction. These results indicate that an increase in the

Table 2.Chemical composition of LBSE. extraction time and the use of successive batch steps can improve the extraction efficiency of stilbenoids from grape canes.

The final extraction was conducted as follows: $0.504 \pm 0.001 \mathrm{Kg}$ of grape canes (dry basis) with a particle length of $1 \mathrm{~cm}$ was extracted with ethanol $(80 \%)$, at a S:L ratio of $1: 10$, at $80{ }^{\circ} \mathrm{C}$ for $100 \mathrm{~min}$ at a pressure between 100 and 200 $\mathrm{KPa}$ (vapor pressure of ethanol/water mixture at this temperature) in a $7 \mathrm{~L}$ stainless-steel batch reactor in two successive extractions.

\subsection{Characterization of final grape cane extract obtained at bench scale}

Based on the preceding results, a grape cane extract was produced at the bench scale $(7 \mathrm{~L})$ under the final conditions described in the previous section. The LBSE was characterized to evaluate the potential of grape canes as an industrial source of stilbenoids for bench scale extraction. The chemical properties of LBSE are summarized in Table 2.

The LBSE contained high levels of sugars, mainly glucose, which can be initially present in canes or can be a product of cellulose hydrolysis during the extraction ${ }^{16}$. A high lignin percentage was also observed which is typical of this type of biomass. The molecular weight distribution of the acetylated lignin was $1893 \mathrm{~g} \mathrm{~mol}^{-1}$ in number $(\mathrm{Mw})$ and $770 \mathrm{~g} \mathrm{~mol}^{-1}$ in weight $(\mathrm{MN})$, with a polydispersity index of 2.4. Taking into account that the main aim is the production of industrial phenolic compounds, all these compounds can be considered as impurities present in the crude extract, however, none of them shows toxicity to human health.

\begin{tabular}{|c|c|}
\hline Parameter & $\% \mathbf{w} / \mathbf{w}$ \\
\hline Moisture & $5.0 \pm 0.1$ \\
\hline Proteins & $6.7 \pm 0.1$ \\
\hline Total sugars & $27.5 \pm 0.1$ \\
\hline Glucose & $21.4 \pm 0.2$ \\
\hline Xylose & UD \\
\hline Arabinose and rhamnose & UD \\
\hline Mannose & $6.1 \pm 0$ \\
\hline Total lignins & $38.7 \pm 1.4$ \\
\hline Insoluble lignins & $34.1 \pm 1.4$ \\
\hline Soluble lignins & $4.6 \pm 0.1$ \\
\hline Number-average molecular weight $\left(M_{\mathrm{n}} ; \mathrm{g} / \mathrm{mol}\right)$ & 770 \\
\hline Weight-average molecular weight $\left(M_{\mathrm{w}} ; \mathrm{g} / \mathrm{mol}\right)$ & 1893 \\
\hline Polydispersity $\left(M_{\mathrm{w}} / M_{\mathrm{n}}\right)$ & 2.4 \\
\hline Ash & 1.03 \\
\hline $\mathrm{Mg}$ & $5.53 \pm 0.03 \times 10^{-2}$ \\
\hline $\mathrm{Ca}$ & $2.34 \pm 0.05 \times 10^{-2}$ \\
\hline $\mathrm{Fe}$ & $2.1 \pm 0.5 \times 10^{-3}$ \\
\hline $\mathrm{Cu}$ & $2.4 \pm 0.3 \times 10^{-3}$ \\
\hline As & UD \\
\hline $\mathrm{Zn}$ & $4.5 \pm 0.1 \times 10^{-3}$ \\
\hline $\mathrm{Pb}$ & UD \\
\hline $\mathrm{K}$ & $8.6 \pm 0.1 \times 10^{-1}$ \\
\hline $\mathrm{Na}$ & $8.01 \pm 0.04 \times 10^{-2}$ \\
\hline
\end{tabular}

UD: undetected 
Toxic elements such as $\mathrm{Pb}$ and As were not detected in the LBSE, while significant amount of $\mathrm{K}$ and $\mathrm{Na}$ were found. Other elements as a $\mathrm{Zn}, \mathrm{Fe}$ and $\mathrm{Mg}$ were also detected in the extract. All these minerals are considered micronutrients: potassium in diet reduces cardiovascular disease and decreases the risk of osteoporosis, $\mathrm{Zn}$ and $\mathrm{Fe}$ are involved in immune system and blood composition and $\mathrm{Mg}$ play an important function in living cells ${ }^{16}$.

The identities and contents of stilbenoids and other phenolic compounds found in the LBSE are summarized in Table 3; the concentrations of the main compounds are also given.

Twelve stilbenoids were detected in the LBSE. Three of them are the most abundant: $E$-resveratrol, $E$ - $\varepsilon$-viniferin, and $(E)$-piceatannol, followed by $E$ - $\omega$ viniferin, vitisin $B$ and a tetramer. Some minor oligostilbenoids like ampelopsin A, $(E)$-piceid and hopeaphenol were also detected. The identities of two dimers at trace levels with maximum absorption at $280 \mathrm{~nm}$ were assigned tentatively as pallidol and isohopeaphenol by comparison with DAD and MS data published by Gabaston et al., $2017^{23}$.
The total stilbenoid concentration was $65300 \pm 469 \mathrm{mg} \mathrm{Kg}^{-1}$ of crude extract [dry weight (DW)]. The stilbenoid profile of the crude extract was similar to that previously reported for Pinot Noir grape canes ${ }^{9}$, despite the important differences between the extraction procedures. This is relevant because it shows that the proposed bench-scale process did not significantly alter the stilbenoid profile of the grape cane extract. The concentration of $E$-resveratrol found in LBSE were 33 times higher than the reported concentration for vine shoot of Melon of Burgundy patent EP2920160A1. For $E$ - $\varepsilon$-viniferin concentration was only 3.7 time higher than the reported example. These differences could be produced by several factors in the process that consisted in a more dynamic extraction due to the extrusion with a smaller sample size (1 to $8 \mathrm{~mm}$ ), lower extraction temperature $\left(60^{\circ} \mathrm{C}\right)$ and a similar extraction time $(2 \mathrm{~h})^{24}$. However, the differences in the $E$-resveratrol concentration are too high to be explained only by the extraction process and must be highly influenced by the grape variety and especially by the post-pruning storage process, inducing an important increment of this stilbenoid, which is available for extraction. The post-pruning storage is a relevant aspect that must be considered in the industrial process, due to their effect in the initial concentration of stilbenoids present in the vegetal material.

Table 3. HPLC-DAD-MS/MS data for phenolic compounds in LBSE.

\begin{tabular}{|c|c|c|c|c|c|c|}
\hline Compound & $t_{\mathrm{R}}(\min )$ & {$[\mathbf{M}-\mathbf{H}]^{-}$} & Fragments & $\lambda_{\max }(\mathrm{nm})$ & $\mathrm{mg} \mathrm{Kg}^{-1}$ (dry weight) & $\%(w / w)$ \\
\hline \multicolumn{7}{|l|}{ Stilbenoids } \\
\hline (E)-Piceid* & 19.6 & 389 & 227 & $306(318)$ & Traces & \\
\hline Ampelopsin A & 23.0 & 469 & $451 ; 423 ; 375 ; 365 ; 345 ; 317 ; 241$ & 282 & Traces & \\
\hline (E)-Piceatannol* & 24.4 & 243 & - & $324(300)$ & 3668 & 0.37 \\
\hline Pallidol & 27.9 & 453 & $359 ; 265$ & $280(285)$ & Traces & \\
\hline (E)-Resveratrol* & 32.2 & 227 & - & $306(318)$ & 30230 & 3.02 \\
\hline Hopeaphenol* & 38.3 & 906 & $358 ; 451 ; 360 ; 718 ; 345 ; 812 ; 265$ & 282 & Traces & \\
\hline Isohopeaphenol & 39.3 & 906 & $359 ; 265 ; 451 ; 317 ; 345 ; 330 ; 813$ & 283 & Traces & \\
\hline$(E)-\varepsilon$-Viniferin* & 43.3 & 453 & $359 ; 347 ; 225 ; 411 ; 279 ; 197 ; 145$ & 323 & 30082 & 3.01 \\
\hline Tetramer & 44.9 & 906 & $680 ; 330 ; 341 ; 319 ; 452 ; 574$ & 299 & 160 & 0.02 \\
\hline$(E)$ - $\omega$-Viniferin & 46.9 & 453 & $411 ; 435 ; 385 ; 359 ; 347 ; 243 ; 225$ & $321(324)$ & 720 & 0.07 \\
\hline Tetramer & 48.2 & 906 & $347 ; 359 ; 451 ; 649 ; 705$ & $318(330)$ & Traces & \\
\hline$(E)$-Vitisin $\mathrm{B}^{*}$ & 54.2 & 906 & $359 ; 347 ; 439 ; 800 ; 279$ & 325 & 440 & 0.04 \\
\hline \multicolumn{7}{|l|}{ Flavan-3-ols / procyanidins } \\
\hline Dimer & 8.4 & 577 & $407 ; 125 ; 289 ; 246 ; 161 ; 203$ & 279 & Traces & \\
\hline (Epi)gallocatechin & 9.3 & 305 & $219 ; 178 ; 125 ; 164 ; 204$ & 272 & Traces & \\
\hline Dimer & 10.2 & 577 & $407 ; 289 ; 125 ; 161 ; 245$ & 283 & 9980 & 1.0 \\
\hline (+)-Catechin* & 11.5 & 289 & $245 ; 203 ; 123 ; 205 ; 137 ; 221$ & 279 & 31700 & 3.17 \\
\hline Dimer & 14.6 & 577 & $289 ; 125 ; 407 ; 245 ; 161$ & 282 & 11100 & 1.11 \\
\hline (-)-Epicatechin* & 13.6 & 289 & $245 ; 203 ; 125 ; 137 ; 179 ; 221$ & 279 & 16690 & 1.67 \\
\hline (Epi)catechin gallate & 20.1 & 441 & $169 ; 125 ; 289 ; 245 ; 227 ; 151 ; 165$ & $269(350)$ & Traces & \\
\hline \multicolumn{7}{|l|}{ Flavonols } \\
\hline Quercetinpentoside & 16.1 & 433 & 300 & 354 & 310 & 0.03 \\
\hline Quercetinpentoside & 17.2 & 433 & 300 & 354 & 290 & 0.03 \\
\hline Quercetin-3- rutinoside* & 17.7 & 609 & 300 & 354 & 160 & 0.02 \\
\hline Quercetinhexoside & 19.3 & 463 & 300 & - & 350 & 0.04 \\
\hline Quercetinhexoside & 19.7 & 463 & 300 & - & 580 & 0.06 \\
\hline Kaempherolglucoside & 23.5 & 447 & $284 ; 255 ; 227 ; 327 ; 299 ; 241 ; 151$ & - & 310 & 0.03 \\
\hline Quercetin-3- rhamnoside* & 23.9 & 447 & 300 & 360 & 270 & 0.03 \\
\hline Quercetin* & 37.4 & 301 & $151 ; 187 ; 255 ; 233$ & - & 220 & 0.02 \\
\hline TOTAL & & & & & 137260 & 13.7 \\
\hline
\end{tabular}

* Identification confirmed with standards 
The data in Table 3 show that other phenolic compounds were also extracted under the optimized extraction conditions. Flavan-3-ols and procyanidins were detected in the crude extract, mainly $(+)$-catechin, $(-)$-epicatechin, and two unidentified dimers of procyanidin. Other flavan-3-ols, (epi)gallocatechin, and (epi)catechin gallate were detected for the first time in a grape cane extract at trace levels. Sánchez-Gómez et al. ${ }^{24}$ and Rajha et al. ${ }^{25}$ reported the presence of $(+)$-catechin and (-)-epicatechin in vine shoots, but not other procyanidins. The concentrations of monomeric procyanidins in the LBSE were higher than those of oligomeric procyanidins. The total concentration of procyanidins, including monomers, was $69470 \pm 698 \mathrm{mg} \mathrm{Kg}^{-1}$ of crude extract (DW), which is the same order of magnitude as the level found for stilbenoids. Several quercetin derivatives were also detected the in LBSE, together with a kaempferol derivate. The total flavonol concentration in the extract was lower than those of the other studied families, reaching a level of $2490 \pm 201 \mathrm{mg} \mathrm{Kg}^{-1}$ of crude extract (DW); however, the mixture of different families of phenolic compounds is interesting in terms of the bioactivities of these compounds. The total concentration of the three groups of phenolics in the LBSE was $13.7 \% \mathrm{w} / \mathrm{w}$, based on dry matter. This is a significant level in a crude product, which could be used as ingredient in food industry.
The stability of stilbenoids in the LBSE was monitored during 3 months. The LBSE was dissolved in $80 \%$ ethanol and stored in darkness at $-18^{\circ}, 4^{\circ} \mathrm{C}$ and room temperature $\left(20^{\circ} \mathrm{C}\right)$ and exposed to light at room temperature. The results showed no variation in stilbenoid concentrations at any of the studied temperatures, being only necessary its protection from light due to the isomerization of $E$-resveratrol.

\subsection{Antioxidant and biological activities of LBSE}

The extraction efficiency in terms of bioactive products was evaluated in vitro using validated antioxidant assays.

The total concentration of the main families of phenolic compound in the methanolic solution of LBSE, determined by HPLC, was 49.6, 21.6 and $43.2 \mathrm{mg}$ $\mathrm{L}^{-1}$ of flavonols, procyanidins and stilbenoids respectively. Based on these concentration, antioxidant capacity was studied comparing with standards. The antioxidant capacities of LBSE and the mix solution prepared with standards of $E$ - resveratrol $\left(49.6 \mathrm{mg} \mathrm{L}^{-1}\right),(+)$-catechin $\left(21.6 \mathrm{mg} \mathrm{L}^{-1}\right)$ and procyanidin B2 (43.2 $\mathrm{mg} \mathrm{L}^{-1}$ ) are summarized in Table 4 . Both solutions were compared with the sum of the antioxidant capacities of the individual standards at these same concentrations.

Table 4. Antioxidant capacity of LBSE.

\begin{tabular}{|l|l|l|l|}
\hline Concentration $\left(\mathrm{mgL}^{-1}\right)$ & $\mathrm{TEAC}_{\mathrm{ABTS}}^{\mathrm{a}}\left(\mathrm{mmol} \mathrm{g}^{-1}\right)$ & $\mathrm{TEAC}_{\mathrm{CUPRAC}^{\mathrm{a}}}\left(\mathrm{mmol} \mathrm{g}^{-1}\right)$ & ORAC-FL $^{\mathrm{a}}\left(\mathrm{mmol} \mathrm{g}^{-1}\right)$ \\
\hline LBSE & $1.954 \pm 0.264$ & $1.918 \pm 0.154$ & $6.895 \pm 0.996$ \\
\hline Synthetic mix of C+P+R $(49.6+21.6+43.2)$ & $1.891 \pm 0.119$ & $2.144 \pm 0.068$ & $19.698 \pm 2.566$ \\
\hline Sum of result of C+P+R & $1.387 \pm 0.044$ & $1.691 \pm 0.017$ & $9.275 \pm 0.310$ \\
\hline
\end{tabular}

${ }^{\mathrm{a}}$ Expressed as Trolox equivalents. Where $\mathrm{C}$ : $(+)$-catechin; P: procyanidin B; R: $(E)$ - resveratrol

No statistical differences were observed for $A_{280}$ between the standard mix and the sum of antioxidant capacity of all standards, as is expected (there are no differences in the amount of phenolics). However, the antioxidant capacity test, especially ORAC, shows higher values for the standard mix solution than the sum of individual standard antioxidant capacities, indicating a probable synergistic effect of compounds when they are mixed. Other authors have reported synergistic effects on the antioxidant capacities of phenolic compounds, especially between $E$ - resveratrol and flavan-3-ols ${ }^{26}$.

The TEAC assay results showed the reducing capacity of the LBSE, while the protecting capacity of the LBSE was demonstrated using ORAC-FL.

The TEAC values obtained for LBSE were similar to the antioxidant levels observed for the standards mix but higher than the sum of individual antioxidant capacity of the standards. On the other hand, protecting capacity measured by ORAC-FL, was lower than the sum of the individual values for each standard and lower than the protecting capacity of the synthetic mixture of standards. These behaviors can be explained due to the presence of other compounds in the crude extract and show that there are important influences of the LBSE matrix on the antioxidant capacity of the extract. Finally, the antioxidant capacity of the product could be considered to be high having as a reference point the ORAC values ranked for different fresh fruits. From this comparison, it can be considered that $1 \mathrm{~g}$ of final product has an equivalent antioxidant capacity as commonly consumed fresh fruits, such us certain varieties of cherries, blueberries and quinces ${ }^{27}$.

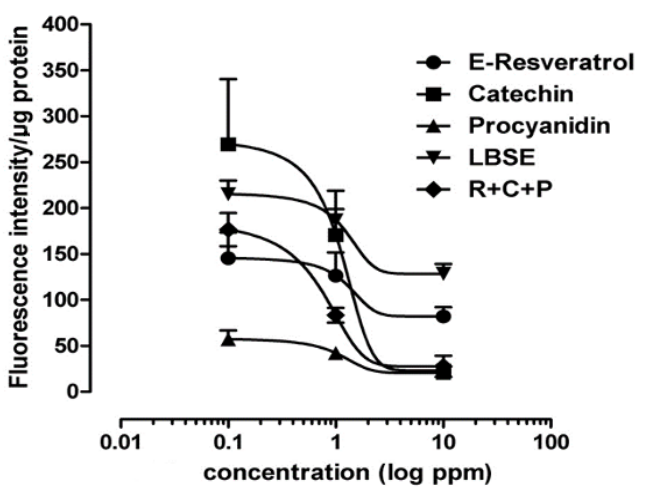

Figure 3. Protecting effect of LBSE, determined using ROS-DCF
The cell-based ROS-DCF assay also showed the protecting effect of LBSE, Figure 3 shows the results obtained for individual standards and a mixture of them at the same concentration found in LBSE, diluted to different levels $(1,10$, and 100 times). The results suggest the protecting capacity of the LBSE, and show a concentration dependence to the individual standards and their mixture. Our results indicate that Procyanidin B had the highest protecting capacity at all dilution levels. The protecting capacity of the LBSE, at all the studied concentrations, was closer to that of the resveratrol standard, and was lower than the protecting capacity of the mixture of standards. This could be caused by competing or antagonistic behavior by the other compounds present in the LBSE.

\section{CONCLUSIONS}

The bench-scale extraction process using post pruning stored Pinot Noir grape canes, produced a natural extract with high levels of stilbenoids $(6.5 \% \mathrm{w} / \mathrm{W}$ DW), flavan-3-ols/procyanidins (6.9 \% w/w DW), lignins, carbohydrates, proteins and some micronutrients. The extraction process carried out with $80 \%$ of potable ethanol using $1: 10$ solid:liquid ratio at $80^{\circ} \mathrm{C}$ for 100 minutes, allowed to produce a natural and stable ingredient with high potential against oxidative damage. It can be used in the food industry, adding value and utilizing a residue from viticulture.

\section{ABBREVIATIONS USED}

ABTS, 2,2'-azino-bis(3-ethylbenzothiazoline-6-sulfonic acid); CUPRAC, cupric ion reducing antioxidant capacity; DCF-DA, dichlorodihydrofluorescein diacetate; LBSE, Lyophilized bench-scale extract; ORAC-FL, oxygen radical absorbance capacity-fluorescein; ROS, Reactive oxygen species; TEAC, Trolox equivalent antioxidant capacity.

\section{ACKNOWLEDGMENTS}

The authors would like to thank Fondef Grant D10I1104, AFB 17007 and doctoral scholarship, all from Conicyt Chile. We would also like to thank Professor Peter Winterhalter, who provided standards, and the Viña de Neira vineyard, for providing raw materials for the study.

\section{REFERENCES}

1. Boue SM, ClevelandTE, Carter-Wientjes C, Shih BY, BhatnagarD, McLachlanJM, BurowME. Phytoalexin-Enriched Functional Foods. $J$ Agric Food Chem 57: 2614-2622 (2009).

2. Diaz-Gerevini GT, Repossi G, Dain A, Tarres MC, Das UN, Eynard AR. Beneficial action of resveratrol: How and why? Nutrition 32:174-8 (2016). 
3. Bagchi, D.; Sen, C.K.; Ray, S.D.; Das, D. Molecular mechanisms of cardioprotection by a novel grape seed proanthocyanidin extract. Mutat Res 523-524: 87-97(2003).

4. Lizarraga, D.; Lozano, C.; Briedé, J. J.; van Delft, J. H. The importance of polymerization and galloylation for the antiproliferative properties of procyanidin-rich natural extracts. FEBS J 274: 4802-4811 (2007).

5. Llopiz, N.; Puiggro, F.;Céspedes, E.; Arola, L. Antigenotoxic effect of grape seed procyanidin extract in FAO cells submitted to oxidative stress. J Agric Food Chem 52: 1083-1087 (2004).

6. Gabaston J, Cantos-Villar E,BiaisB,Waffo-TeguoP,Renouf E,CorioCostet M, Richard T,Mérillon J. Stilbenes from Vitisvinifera L. Waste: A Sustainable Tool for Controlling PlasmoparaViticola. J Agric Food Chem 65: 2711-2718 (2017).

7. Flamini, R.; Rosso, M. De.; Marchi, F. De. An innovative approach to grape metabolomics: stilbene profiling by suspect screening analysis, Int J Mol Sci 14:1243-1253(2012).

8. Vergara C, Von BaerD, Mardones C,Wilkens A,Wernekinck K,Damm A, Macke S,Gorena T,Winterhalter P. Stilbene levels in grape cane of different cultivars in southern Chile: Determination by HPLC-DADMS/MS method. J Agric Food Chem 60: 929-933 (2012).

9. Gorena, T.; Sáez, V.; Mardones, C.; Vergara, C.; Winterhalter, P.; von Baer, D. (2014). Influence of post-pruning storage on stilbenoid levels in Vitis vinifera L. canes. Food Chem 155: 256-263 (2014).

10. Karacabey, E.; Mazza, G. Optimization of solid-liquid extraction of resveratrol and other phenolic compounds from milled grape canes (Vitisvinifera). J Agric Food Chem 56: 6318-6325 (2008).

11. Karacabey, E.; Bayindirli, L.; Artik, N.; Mazza, G. Modeling solid-liquid extraction kinetics of trans-resveratrol and trans- $\varepsilon$-viniferin from grape cane. J Food ProcessEng 36: 103-112 (2013).

12. Piñeiro, Z.; Guerrero, R. F.; Fernández-Marin, M. I.; Cantos-Villar, E.; Palma, M. Ultrasound-assisted extraction of stilbenoids from grape stems. J Agric Food Chem 61: 12549-12556 (2013).

13. Bart, H. J. \&Pilz, S. Industrial Scale Natural Products Extraction. (Wiley, 2011).

14. Sluiter, A.; Hames, B.; Ruiz, R.; Scarlata, C.; Sluiter, J.; Templeton, D.; Crocker, D. NREL/TP-510-42618 analytical procedure - Determination of structural carbohydrates and lignin in Biomass. https://www.nrel.gov/docs/gen/fy13/42618.pdf [2 October 2015].

15. Ku, C. S.; Mun, S. P. Characterization of proanthocyanidin in hot water extract isolated from Pinus radiata bark. Wood Sci Technol 41: 235-247 (2007).

16. Çetin, E. S.; Altinöz, D.;Tarçan, E.; GöktürkBaydar, N. Chemical composition of grape canes. Ind Crops Prod 34: 994-998 (2011).

17. Ribeiro, J.P.N.; Magalhães, L.M.; Reis, S.; Lima, J.L.F.C.; Segundo, M. A. High-throughput total cupric ion reducing antioxidant capacity of biological samples determined using flow injection analysis and microplate-based methods. Anal Sci 27: 483-488 (2011).

18. Karacabey, E. \& Mazza, G. Optimisation of antioxidant activity of grape cane extracts using response surface methodology. Food Chem 119: 343348 (2010).

19. Wolfe, K.L.; Rui, H.L. Cellular antioxidant activity (CAA) assay for assessing antioxidants, foods, and dietary supplements. J Agric Food Chem 55: 8896-8907(2007).

20. Brewer, L. R.; Kubola, J.; Siriamornpun, S.; Herald, T. J.; Shi, Y. C. Wheat bran particle size influence on phytochemical extractability and antioxidant properties. Food Chem 152: 483-490 (2014).

21. Hemery, Y. M.; Anson, N. M.; Havenaar, R.; Haenen, G. R. M. M.; Noort, M. W. J.; Rouau, X. Dry-fractionation of wheat bran increases the bioaccessibility of phenolic acids in breads made from processed bran fractions. Food Res Int 43: 1429-1438 (2010).

22. Gil, M.; González, A.; Gil, A.Evaluation of milling energy requirements of biomass residues in a semi-industrial pilot plant for co-firing. http://www.bioscale.es/wp-

content/uploads/downloads/2014/04/Evaluation-of-milling-energyrequirements-of-biomass-residues-for-cofiring.pdf [11 [16March 2016].

23. Gabaston J, Cantos -Villar E, Biais B, Waffo-Teguo P, Renouf E, CorioCostet M, Richard T, Mérillon J. Stilbenes from Vitisvinifera L. Waste: A Sustainable Tool for Controlling Plasmoparaviticola. J. Agric Food Chem 65: 2711-2718 (2017).

24. Sánchez-Gómez, R.; Zalacain, A.; Alonso, G.L.; Salinas, M.R. Vine-shoot waste aqueous extracts for re-use in agriculture obtained by different extraction techniques: Phenolic, volatile, and mineral compounds. J Agric Food Chem 62: 10861-10872 (2014).
25. Rajha, H.N.; Boussetta, N.; Louka, N.; Maroun, R.G.; Vorobiev, E. A comparative study of physical pretreatments for the extraction of polyphenols and proteins from vine shoots. Food Res Int 65: 462468(2014).

26. Skroza, D.; Generalić, I.; Svilović, S.; Šimat, V.;Katalinić, V. Investigation of the potential synergistic effect of resveratrol with other phenolic compounds: A case of binary phenolic mixtures. J Food Comp. Anal 38:13-18 (2015).

27. Speisky, H.; López-Alarcón, C.; Gómez, M.; Fuentes, J.; SandovalAcuña, C. First web-based database on total phenolics and oxygen radical absorbance capacity (ORAC) of fruits produced and consumed within the south Andes region of South America. J.Agric Food Chem 260: 88518859 (2012). 